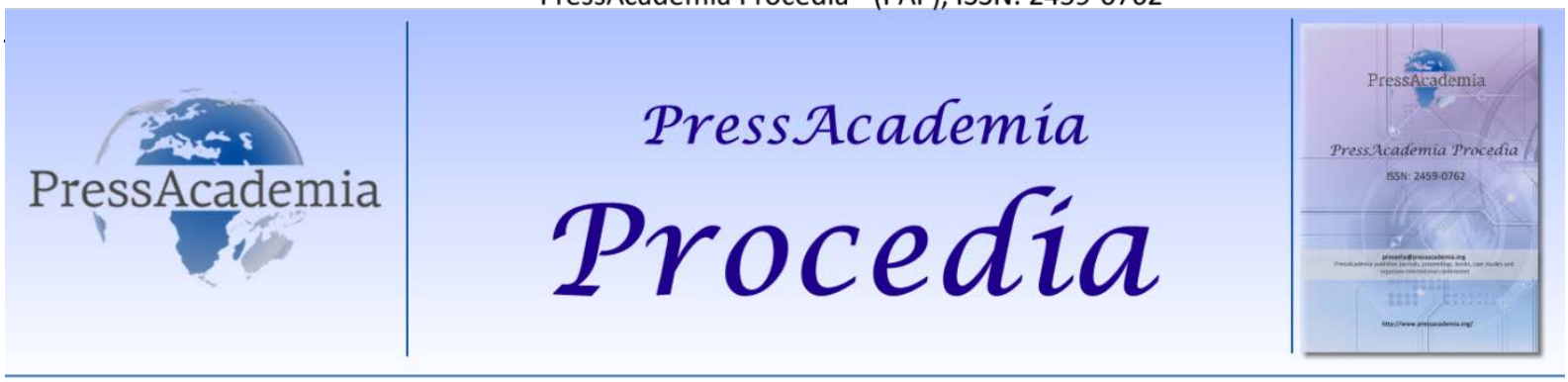

Global Business Research Congress (GBRC), May 26-27, 2016, Istanbul, Turkey.

\title{
DO PERSONALITY TRAITS PLAY A DETERMINANT ROLE IN ENTREPRENEURSHIP?
}

\section{DOI: 10.17261/Pressacademia.2016118671}

\author{
Gulseren Keskin ${ }^{1}$, Gulay Tasdemir ${ }^{2}$, Elif Aktekin ${ }^{3}$, Sureyya Gumussoy ${ }^{4}$ \\ ${ }^{1}$ Ege Üniversitesi. gulseren.keskin@ege.edu.tr \\ ${ }^{2}$ Pamukkale Üniversitesi. gtasdemir@gmail.com \\ ${ }^{3}$ Ege Üniversitesi . elif aktekin@hotmail.com \\ ${ }^{4}$ Ege Üniversitesi. sureyya.s@hotmail.com
}

\begin{abstract}
Recently, entrepreneurship is emerging as an important concept in creating economic growth and employment. The human factor is the structure should be evaluated primarily on entrepreneurship. This study aimed to examine the relationship between entrepreneurial individual personality characteristics. Method: The articles that are related with entrepreneurship, personality, neurosis, extroversion were searched by key words in PubMed, Medline, EBSCOHost, PsycINFO, Science Direct, Turkish Medline, Çukurova Index Databases and in Google Scholar and those appropriate for this review were used by authors. Expected Results: Conclusion: Our study revealed the influence of individual differences on entrepreneurship. studies showing that impact on the behavior of personality traits, will be a guide to future entrepreneurs. Personality include sustainability aspects of individual's mental, emotional, social and physical . Meta-analytic studies showed that individual differences effect on entrepreneurial orientation. Entrepreneurs were determined to be risk-taking, innovative, high sense of responsibility, high communication skills individuals. Especially in biological studies, it was determined that extraversion and neurotic structure increase entrepreneurship.
\end{abstract}

Keywords : Entrepreneurship, personality, extroversion, neurosis

JEL Codes: M12, M13, I12

\section{GiRişiMCiLIKTE KişiLiK ÖZELLiKLERi BELIRLEYici MidiR?}

\section{ÖZET}

Son zamanlarda girişimcilik ekonomik büyüme ve istihdam yaratılmasında önemli bir kavram olarak dikkati çekmektedir. İnsan faktörü girişimcilikte başta değerlendirilmesi gereken yapıdır. Bu çalışmada girişimcilikle bireysel kişilik özelikleri arasındaki ilişkinin incelenmesi amaçlanmıştır. Pubmed, Medline, EBSCOHost, PsycINFO, Türk Medline veri tabanlarında ve Google Akademik'te yer alan girişimcilik, kişilik gibi anahtar kelimeler kullanılarak ilgili makaleler taranmış ve gözden geçirme için uygun olan çalışmalardan yararlanılmıştır. Kişilik, bireyin zihinsel, duygusal, sosyal ve fiziksel özelliklerinin süreklilik gösteren yönlerini içerir. Meta-analitik çalışmalar bireysel farklııkların, girişimcilik eğilimleri üzerinde etkili olduğunu ortaya koymuştur. Girişimcilerin risk alabilen, yenilikçi, sorumluluk duygusu yüksek, iletişim becerileri yüksek bireyler olduğu belirlenmiştir. Özellikle biyolojik çalışmalarda dışadönüklük ve nevrotik yapının girişimciliği arttırdığı belirlenmiştir. Bizim çalışmamız bireysel farklılıkların girişimcilik üzerine etkisini ortaya koymuştur. Kişilik özelliklerinin davranışlar üzerinde etkili olduğunu gösteren çalışma, gelecekteki girişimcilere rehber olabilecektir.

Anahtar Kelimeler: Girişimcilik, kişilik, dışa dönüklük, nevroz

JEL Kodları: M12, M13, I12 


\section{GíRiş}

Girişimcilik, istihdam hacminin arttırıması, sosyal hareketliliğin hız kazanması, yerel kaynakların hızlı ve etkin biçimde kullanılmasının sağlanması gibi sosyo-ekonomik yapıda yaptığı değişimler nedeni ile çok boyutlu bir yapıya sahip olduğu düşünülür. Girişimci bireylerin sıklıkla üretime dayalı aktiviteleri tercih ettikleri saptanmıştır. Gelişmekte olan ülkelerde işgücünün büyük paydası sıklıkla kendi işlerini kuran, yenilikçi bireylerden oluştuğu belirlenmiştir. Az gelişmiş ekonomilerde girişimcilik faaliyetleri yenilikçilikle desteklenerek geliştirilmesi, ekonomik büyümenin özel bir koşulu olarak önerilmektedir. Girişimci bireyler yeni ürün ve pazar fırsatlarının yaratılması, yenilikçi bir ortam oluşturulması, yatırımcı ilişkilerinin geliştirilmesi, kritik alanlardaki insan kaynaklarının geliştirilmesine dair bir çok görevi başarı ile gerçekleştirebilecek potansiyele sahiptirler. Yenilikçi ve yeni fikirleri hızla devreye sokabilen bireylerin beklenmeyen durumlarda, ortaya çıkan problemleri hızla çözebilme kapasitesine de sahip oldukları belirlenmiştir. Bu nedenle girişimcilikte yeni bir ürün ortaya koyma sürecinde bireysel özellikler oldukça önem kazanmaktadır.

\section{LITERATÜR TARAMASI}

Girişimci basitçe herhangi bir alandaki girişimini uygulama safhasında risk almaya istekli olan bireydir. Schumpeter bu bireyleri 'sosyolojik olarak farklı' bireyler olarak tanımlar. Literatürde girişimci bireylerin sürekli başarma ihtiyacı olan, risk alabilen, cesur, yaratıcı, özgüveni yüksek, kendini kontrol edebilen ve stres toleransı yüksek bireyler olduğu bildirilmiştir. Girişimci bireyler yenilikçi yapısı nedeni ile fırsatları yakalayabilen kişidir. Belirsizliğe karşı toleransları yüksek bireyler oldukları için, risk almaktan kaçınmazlar. Kendilerine ulaşılması daha güç hedefler koyarlar, başarmaya yönelik açlıklarının mükemmeliyetçi yönleri ve özgüvenli ile desteklenmesiyle kolaylıkla sorumluluk alabilirler. Bu özelikleri onları hızla değişen şartlara uyarlama ve rekabet üstünlüğünü elde etme şansını verir. Ancak yalnızca bu özelliklere sahip olmak girişimcinin başarılı olmasını sağlamada yeterli olmamaktadır. Son yıllarda girişimciliğin nörotik yapı, dışadönüklük gibi kişilik özellikleri ile bağlantısı olabileceği düşünülmektedir.

\section{VERI VE YÖNTEM}

Çalışma, Pubmed, EBSCOHost, Science Direct, Ulakbim Tıp Veri Tabanı, Türk Medline veri tabanları kontrol edilerek yürütülmüştür. İngilizce anahtar kelimeler için MeSH (Medical Subject Headings) dizini ve dizinde yer almayan ilgili anahtar kelimeler, Türkçe anahtar kelimeler için TBT'de (Türkiye Bilim Terimleri) yer alan sözcük olan "girişimcilik, kişilik, dışa dönüklük, nevroz" ile İngilizce anahtar sözcüklerin Türkçe çevirisi kullanılmıştır. Sonuncusu nisan 2016'da yapılan taramalar, belirlenen anahtar kelimeler ile çeşitli kombinasyonlar yapılarak tamamlanmıştır.

Dahil edilme ölçütleri Yüksek dereceli kanıt düzeyine ulaşmak için çalışmaya randomize kontrollü çalışmalar (RKÇ) (Harbour ve Miller 2001), Türkçe ve İngilizce dillerinde yazılmış, tam metin makaleler dahil edilmiştir. Buna göre girişimcilik ve girişimciliğin kişilik boyutunun değerlendirildiği çalışmalar bu sistematik derlemeye alınmıştır. Makale seçimi Aramalar ilk aşamada altı veri tabanında yürütülmüş ve ilgili başlıklar/özetler incelemeye alınmıştır $(n=100)$. Araştırmaların arasında çalışmanın amacına uygun olanlar belirlenmiştir $(n=17)$. Potansiyel çalışmaların tam metinleri elde edildikten sonra dahil edilme ölçütlerine uygun olan makaleler seçilmiştir..

\section{BULGULAR VE TARTIŞMA}

Kişilik, bireyi başkalarından ayıran, kendi içinde tutarlı olan ve süreklilik arz eden, doğuştan getirdiği, ve sonradan kazanılan özelliklerin bütünüdür. Kişilik, bireyin fiziksel ve sosyal ortamıyla etkileşim biçimini tanımlayan, düşünce, duygu ve davranışın ayırt edici ve karakteristik örüntülerdir. Kişilik değerlendirilirken sadece kişinin bireysel özellikleri değil aynı zamanda toplum içerinde ve grup içerindeki özellikleri de değerlendirilir.

Meta-analitik çalışmalar bireysel farklıııların, girişimcilik eğilimleri üzerinde etkili olduğunu ortaya koymuştur (Stewart ve Roth, 2004; Zhao ve Seibert, 2006 ). Özellikle biyolojik çalışmalarda dışadönüklük ve nevrotik yapının girişimciliği etkilediği belirlenmiştir. Nevrotiklik depresyon, dürtü denetim bozukluğu ve güvensizlikte 
olduğu gibi duygusal açıdan kararsız, sinirli, kaygılı, güvensiz, duygusal ve mantık dışı davranışlar göstermeye yönelik yatkınık ve olumsuz duyguları yaşamaya eğilimli insanları ifade eder. Bireydeki nevrotik yapı azaldıkça özgüven, rahatık, kendinden emin olma ve sakin, sabırlı olma artmaktadır. Nevrotik yapının varlı̆ı bireyi girişimcilikten uzaklaştırmaktadır. Özellikle, nevrotik yapısı daha düşük olan bireylerin merkezi pozisyonları daha kolay elde ettiği ve dostluk ilişkilerini daha kolay geliştirdiği bildirilmiştir. Sosyal ağlar, potansiyel girişimcilerin başarısı için çok önemlidir. Çatışmaların çözümlenmesinde sağlıklı kurulan sosyal ağların rolü büyüktür. Nevrotik bireylerin çatışmayı azaltıcı ve çatışmadan kaçınmacı; nevrotikliği düşük olanların ise çatışmaya yaklaşmacı ve yüzleşmeci bir tutum izledikleri görülmektedir. Bu bireyler çatışma ile karşı karşıya kaldıklarında rekabet ve kaçınma stratejileri kullanmayı daha fazla tercih etmekte, uzlaşma ve işbirliği gibi çatışma çözme stratejileri ve problem çözme stratejilerinden uzak kalmayı terci etmektedirler (Karanci ve ark 2007).

Nevrotik yapı aynı zamanda duygusal tutarsızlı̆ı veya aşırı tepkiselliği de destekler. Bu kişilerin kaygılı, depresif, gergin, çekingen, aşırı duygusal düşük öz-güvenli yapıları nedeni ile duygusal dengesinde sıkıntılar yaşanabilmektedir. Girişimci olmak ise, beraberinde duygusal denge sahibi olmayı gerektirmektedir. Çünkü girişimciler ağır iş yükü, riskli durumlar, sosyal baskı, finansal zorluklar ve bu sorunların getirdiği stresle karşı karşıya kalmaktadırlar. Bu durum nevrotik yapının girişimcilik davranışını engellediğini göstermektedir (Shane,2010: 155).

İrade gücü Gollwitzer ve Heckhausen tarafından girişimcilikte eylemi başlatan önemli karakteristik özellik olarak nitelendirilmiştir. Birey yüksek irade gücü sayesinde korkmadan özgün fikirlerini hayata geçirebilir. İradeli bireyler öz disiplin gücü yüksek bireylerdir. Bir karar aldıktan sonra, bu kararı başarıyı ede edene kadar sürdürme yeteneğine sahiptirler, bu özellik onların girişimcilik faaliyetlerinde başarılı olmalarını sağlar. .

Dışa dönüklük kolay iletişim kurmayı, girişkenliği, kişiler arası ilişkilerde rahatlı̆̆ı, sosyal olmayı gerektiren bir kişilik özelliğidir. Bu özelliği sayesinde kolay iletişim kurarlar, kolay arkadaş edinirler. Kişilerarası etkileşim gerektiren işlerde yüksek performans sergileyebildiklerinden kolaylıkla grup lideri olabilirler. Sosyal yeteneği oldukça yüksek olduğundan girişimcilik yönü fazladır (Robbins, Judge, 2009:144, Özdevecioğlu ve ark 2013). Kendilerinde var olan yüksek enerji potansiyeli sayesinde daha kısa sürede daha fazla iş tasarlayıp, daha az şikayet ederler. Dışa dönük olma sosyalliği ve dürtüselliği de beraberinde getirir. Genellikle değişiklikten hoşlanırlar, kaygısız, kayıtsız ve sıkıntısızdılar fakat kolay sinirlenip kendini kaybedip, duygularını kontrol etmede ve kendilerini engellemede her zaman başarılı değildirler. Dışa dönük bireyler, içe dönüklere oranla daha fazla enerjiye, pozitif etkiye ve pozitif olay beklentisine sahiptirler ve ödüle karşı daha fazla duyarlıdırlar (Atak 2013). (Basım et al 2009). (Bozionelos, 2004:70). Dışadönükler sıklıkla kolay iletişime geçen, girişken, yalnızlığı tercih etmeyen olumlu yanları ile sosyal iletişim becerileri yüksek; baskın yönleri ile kolaylıkla çatışmaya giren bir özellik sergilerler. Tüm bunlar dikkate alındığında dışadönük kişilerin girişimci kişiler olduğu söylenebilir.

Yazında psikotizm ile girişimcilik arasındaki ilişki sorgulanmış, psikotizmin soğuk, mesafeli, saldırgan, güvensiz, duygusuz özelliklerinin yanında yaratıcılıklarının oldukça yüksek olduğu bildirilmiştir. Psikotik bireylerde olduğu gibi girişimci bireylerde de olağanüstü, yaratıcı, kapsamlı düşünce tarzı hakimdir. Yaratıcı kişiler toplum tarafından normal olarak tanımlanan bireylerden biraz farklı bireylerdir Yaratıcı bireyler özgün ve çabuk düşünebilme yetisi, yeniliğe açık olma, ilgi alanlarının çok yönlü olması, konulara-sorunlara farklı açılardan yaklaşabilme becerisi, başarılı olma hevesi, içe dönük veya coşkulu bir yapıda olma, sezgilerinin güçlü olması, etkileyici olma ile toplumun normal olarak gördüğü bireylerden biraz sapma gösterirler Psikotizmin özellikleri içinde yer alan özgünlük, sorunlara farklı açıdan bakabilme, yaratıcılıklarını toplumdan soyutlanarak gerçekleştirme, girişimci bireylerin de özellikleri ile benzerlik göstermektedir. Girişimci bireylerin karar vermede sezgisel gücünün yüksek, yeniliklere açık, yaratıcı yönleri ile bu bireylerin psikotizm benzeri özellikler sergilediklerini de düşündürmektedir.

\section{SONUÇ}

Çalışmamız girişimcilikte bireysel farkıııkların etkili olduğuna yönelik kanıtları ortaya koymaktadır. Dışadönüklük, psikotizm, nevrotik yapı, irade gücü, yaratıcılık gibi özelliklerin girişimciliğe yönelik etkinliklerde 
belirleyici olmaktadır. Başarılı girişimler yetenekli girişimciler sayesinde olduğu dikkate alındığında, başarılı girişimlerin seçiminde girişimcilerin karakteristik özelliklerinin önemsenmesi gerektiği unutulmamalıdır.

\section{KAYNAKLAR}

Antonio,T., Lanawati, S., Wiriana, T.A. \& Christina, L.(2014). Correlations Creativity, Intelligence, Personality, and Entrepreneurship Achievement. Procedia - Social and Behavioral Sciences, 115,251-257

Atak, H.(2013). On-Maddeli Kişilik Ölçeği'nin Türk Kültürü’ne Uyarlanması Nöropsikiyatri Arflivi 50, 312-319

Basım, H. N., Çetin, F. \& Tabak, A. (2009). Beş faktör kişilik özelliklerinin kişilerarası çatışma çözme yaklaşımlarıyla ilişkisi Türk Psikoloji Dergisi, 63,20-34.

Boz, A. \& Ergeneli, A.(2014). Women entrepreneurs' personality characteristics and parents' parenting style profile in Turkey. Procedia Social and Behavioral Sciences 109, 92 - 97.

Brandstätter, H.(2011). Personality aspects of entrepreneurship: A look at five meta-analyses Personality and Individual Differences, 51,222-230.

Eyre, H.A., Lindsay, T., Churchill, J.A., Cronin, O. \&Meyers, A.(2015). Fostering creativity and innovation in the health system: the role of doctors-in-training in biomedical innovation and entrepreneurship. Med J Aust. 20,68-7

Fairlie, R. W. \& Holleran, W. (2012). Entrepreneurship training, risk aversion and other personality traits: Evidence from a random experiment. Journal of Economic Psychology 33,366-378

Hikkerova, L., Nyock llouga, S. \& Sahut J.M. (2016). The entrepreneurship process and the model of volition. Journal of Business Research 69, 1868-1873.

İlhan, S. (2004). Girişimcilik ve sosyo-ekonomik süreçteki rolü. Süleyman Doğu Anadolu Bölgesi Araştırmaları 70-75.

İrengün, O. \& Arıkboğa, Ş. (2015). The Effect of Personality Traits on Social Entrepreneurship Intentions: A Field Research. Procedia - Social and Behavioral Sciences, 195,1186-1195.

Jahani, S., Abedi, H., Elahi, N. \&Fallahi-Khoshknab, M. (2016).Iranian entrepreneur nurses' perceived barriers to entrepreneurship: A qualitative study. Iran J Nurs Midwifery Res.21,45-53.

Karimi, S., Biemans, H.J., Naderi Mahdei, K., Lans, T., Chizari, M \& Mulder, M. (2015).Testing the relationship between personality characteristics, contextual factors and entrepreneurial intentions in a developing country. Int J Psychol. Sep 3.

Kranci, N., Dirik, G. \& Yorulmaz, O.(2007). Eysenck Kişilik Anketi -Gözden Geçirilmiş Kısaltılmış Formu'nun (EKA-GGK) Türkiye'de Geçerlik ve Güvenilirlik Çalışması. Türk Psikiyatri Dergisi 18,22-27.

Obschonka, M. Schmitt-Rodermund, E. \&Terracciano, A.(2014). Personality and the gender gap in self-employment: a multi-nation study.. PLoS One 4,8, e103805.

Özdevecioğlu, M., Kaya, Y \& Dedeoğlu, T. (2013). Kişilik özelliklerinin izleyici etkisi (bystander effect) üzerindeki etkisinde kontrol odağının rolü. Erciyes Üniversitesi İktisadi ve İdari Bilimler Fakültesi Dergisi, 42, 25-40

Tatılıığlu, K. (2014). Üniversite öğrencilerinin beş faktör kişilik kuramı’na göre kişilik özellikleri alt boyutlarının bazı değişkenlere göre incelenmesi. Tarih Okulu Dergisi 7, 939-971

Zhang, Z., Zyphur, M.J, Narayanan, J., Richard, D. A., Chaturvedi, S., Avolio, B.J , Lichtenstein, P. \&Larsson, G. (2009). The genetic basis of entrepreneurship: Effects of gender and personality Organizational Behavior and Human Decision Processes 110, 93-107 